\title{
CHAKRAS, THE WHEELS OF LIFE: A NEW PARADIGM FOR HUMAN HEALTH, RELATIONSHIP AND DISEASE
}

\author{
C D. MARATHE ${ }^{1} *$ \& JAGDISH ACHARYA ${ }^{2}$ \\ ${ }^{1}$ Satish Pradhan Dnyanasadhana College, Thane 400604, Maharashtra, India \\ ${ }^{2}$ Sadguru Academy, At and Post Panchwad, Taluka Wai, Dist. Satara, Maharashtra, India
}

\begin{abstract}
The Sanskrit word Chakra means "plexus," "wheel," or "vortex." The Chakra system originated in India between 1500 and $500 \mathrm{BC}$ in the oldest texts called the Vedas. The knowledge of this system was propagated further down through Indo-European people called Aryans. The chakras are invisible or beyond our perception. They are treated as energy centres in the body located in the spinal region. There are seven major chakras and each Chakra represents a level of consciousness. It is believed that the chakras vitalize the physical body and influence physical, emotional and mental dynamics. The Chakras are believed to be associated with the major nerve networks within the body. The Chakras connect the brain/spine, via the major Vagus nerve, to the glands responsible for hormone production and the overall functioning of the body. There is a correspondence between the position and role of the chakras and those of the glands in the endocrine system. The objective of this study is to relate the traditional concept of Chakras present in the body to human health, relationship and disease.

KEYWORDS: Seven Chakras, Five Nature Elements, Sensory Organs, Life Energy, Chakra Balancing, Open Chakra, Blocked Chakra \& Vagus Nerve
\end{abstract}

Received: Jun 09, 2020; Accepted: Jun 29, 2020; Published: Jul 18, 2020; Paper Id.: IJMPERDJUN2020383

\section{INTRODUCTION}

Chakra (pronounced as 'Chuhk-ruh) is an ancient Indian concept, deriving back from the Vedas, also the Upanishads and the Yog Sutras of Patanjali. The term 'Chakra' has its origin in a Sanskrit word which means 'wheel'. Chakras (plural) are swirling wheels of energy which provide vital force for life as regards health (both physical and emotional) and spiritual comfort. Chakras are various focal points or energy centres used in a variety of ancient meditation and Yoga practices. The term Chakra is used to describe the way energy moves in the body. They are associated with interactions of physical, emotional and mental nature. We find references to as many as 88000 chakras in the human body, of which six principal chakras are situated in the spinal region and the seventh just above the crown of the skull. These seven chakras are described as being aligned in an ascending column from the base of the spine to the top of the head. The seven chakras are associated with seven colours in the rainbow. They are visualised as a Lotus or flowers with different numbers of petals. It is also assumed that out of these seven chakras, five are associated with the five nature elements in Yogic Science with their Sanskrit names, viz Earth (Prithvi), Space (Akash), Water (Aap or Jal), Fire (Agni) and Air (Vayu). All seven chakras have associated colours, sense organs, and organs of action. They are further associated with multiple physiological functions. The names of the seven principal chakras and their respective positions indicative of their physiological aspects.

The seven Chakras with their Sanskrit names are as follows. 
- $\quad$ The Root Chakra (Muladhara)

- The Sacral Chakra (Swadhishthana)

- $\quad$ The Solar Plexus Chakra (Manipura)

- $\quad$ The Heart Chakra (Anahata)

- $\quad$ The Throat Chakra (Vishuddha)

- $\quad$ The Third Eye Chakra (Ajna)

- $\quad$ The Crown Chakra (Sahasrara)

These chakras are all located in areas that are important for regular function. Although they appear to be abstract, they align with bodily functions that are important and easily influenced through outside behaviours. Knowing why chakras control certain things can help us in our journey to healing. Chakras are an integral part of Yoga and get activated through controlled breathing known as Pranayam and Asanas (specific body postures). Motor and sensory nerves play an important part in directing energy upwards in the spinal cord. This flow of energy controls the power of consciousness in the brain. Chakra are linked not only with the five sensory organs but also with other organs.

\section{The Seven Chakras:}

The position of the chakras and their functioning regions or areas have been discussed in details in various ancient texts.

1. Muladhar (Root Chakra): Mula means root, adhar means support. Muladhar Chakra is symbolised by a four-petal lotus, the colour assumed to be red, the first colour of the rainbow. It further associated the nature element 'earth'. It is located at the base of the spine and encompasses the last three vertebrae, bladder and the colon. The functionality of this chakra is related to survival, security, strength and power. Since the location of the chakra is at the centre of the body, its proper balancing is essential for solid foundation and support. Sensory organ of this chakra is nose (Smell).

2. Swadhishthan (Sacral) Chakra: Swa means one's own and adhishtan means dwelling place. This chakra is located right above the Root chakra in the pelvic region. It is associated with kidney, bladder, reproductive system, genitals and is characterized by emotions, sexuality, creativity, and fantasies. Swadhishthan Chakra is associated with the nature element 'water' and the sensory organ tongue (taste). It is the seat of vitality symbolised by a six petal Lotus with orange colour.

3. Manipura (Solar Plexus) Chakra: Mani means jewel and pura means city (City of Jewels). It is like a shining jewel or lustrous gem. Manipura chakra is the seat of our personal power, respect and self-esteem. It is located over the stomach at the level of the naval, below the rib cage. It is associated with mind or intellect. It is linked with the digestive system, pancreas, liver, intestines, lungs, and stomach. This chakra is symbolised by a ten petal Lotus and yellow colour. It is associated with the sensory organ eye (sight) and the nature element 'fire'.

The three chakras mentioned so far are lower chakras as their positions are in the lower portion of the body, especially below the heart. They lie over a major part of the excretory organs. They relate to the physical, emotional and intellectual aspects of life. 
From the fourth chakra onwards, our energy begins to shift from a focus on the individual self towards a more generous self, i.e. a self showing unselfish concern for the welfare of the others. The direction of the energy in the body begins to flow upwards to reconnect to the greater source of the divine love.

4. Anahat (Heart) Chakra: This is the middle of the seven chakras located at the centre of the chest at the heart level. Anahat means unstuck, unbeaten or unharmed. Although called the heart chakra, the organ most associated with it is the thymus. Other associated organs are heart, lungs, respiratory system, circulatory system, Vagus nerve (also called X cranial Nerve), rib cage, thoracic vertebrae, chest, breast, upper back, shoulders, arms, and skin. It relates to love, compassion and forgiveness. Symbolised by a twelve petal Lotus, this chakra is associated with green colour, sense 'touch' and the nature element 'Air'.

5. Vishuddha (Throat) Chakra: Vishuddhi means Purity. The key aspects of this energy centre are communication and purity. Located near the neck and the shoulder region, it is symbolised by a sixteen petal Lotus and sky-blue colour. It is associated with sense organ ear (hearing) and the nature element 'Akash'. It is mainly associated with vocal cord along with other organs and systems such as respiratory system, cervical vertebrae, throat, jaw, neck, tonsils, larynx, mouth, voice, oesophagus, bronchi, arms, and hands.

6. Ajna (The Third Eye) Chakra: The word Ajna means to perceive, to command or order. This chakra works on the mind and is associated with the thyroid, which controls growth and metabolism in the human body. Mainly associated with speech and expression, this chakra is also linked with the lower part of the brain, ears, nose, left eye, nervous systems, sinuses, and forehead. It is symbolised by a two-petal Lotus and indigo colour. This chakra is not associated with any nature element as it is considered beyond the physical elements. However, it is associated with intuition (Light), commonly called the sixth sense. It is also known to be the centre of vision, prophecy, imagination, inner knowing and self-assurance.

7. Sahasrara (The Crown) Chakra: Sahasra means one thousand. This chakra is not located in the body but hovers above the crown of the head. It is assumed to be facing upwards. It connects to beauty itself and the spiritual realm. It helps one to understand 'who am I' beyond one's physical self, i.e. one is a spiritual being having a human life experience. This chakra is symbolised by a thousand petal Lotus, purple colour (or white which includes all the colours of the rainbow). The Organs and systems associated with this chakra are the upper part of the brain, right eye, controls cerebrum, hemisphere, central nervous system, spinal cord and brain system. 


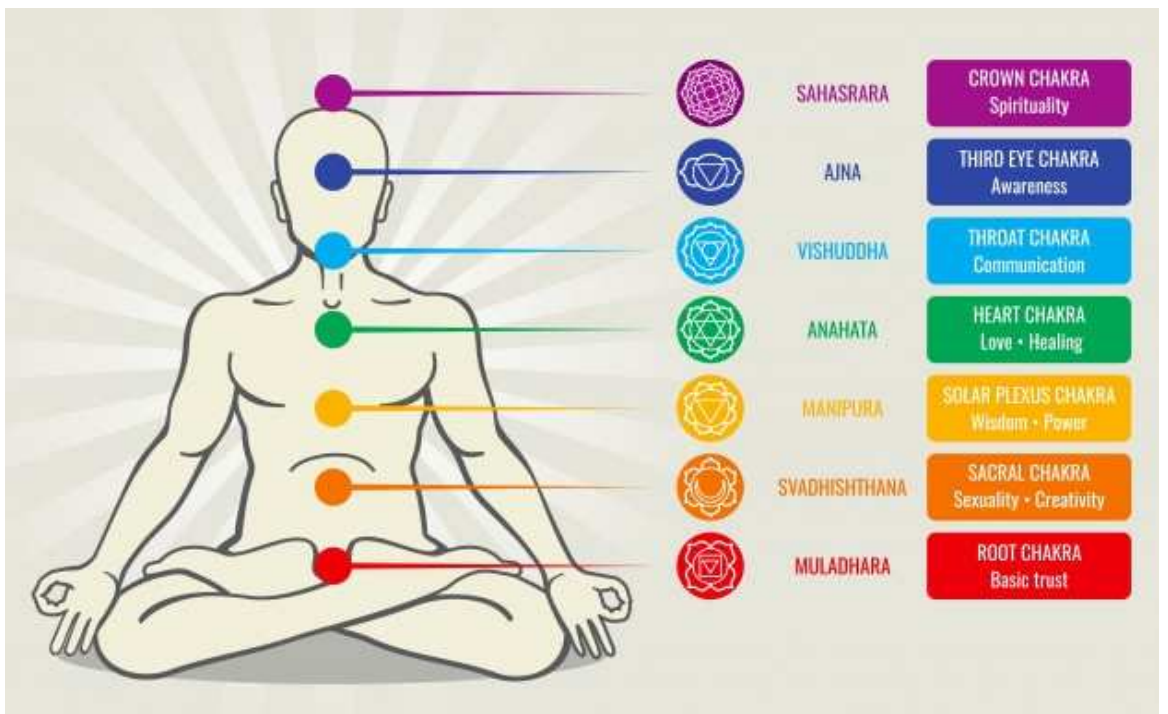

The energies associated with Chakras in the body are not yet recognized by many in the Western world, who believe there is no scientific proof of their existence. It would certainly not be recognized by majority working in modern medicine. However, everybody believes in the energy within the body. One can think of the mind. Everybody believes that exists although physical location in the body is difficult to determine. Likewise, one has to accept the concept of chakras. Those who have believed inexistence of the chakras and have experienced it, tend to work in their own therapeutic practices alongside one or two complementary therapies like healing and counselling sessions.

\section{OBSERVATIONS, RESULTS AND DISCUSSIONS}

Our thoughts control the flow of energy within and around us. It is said that 'thoughts come first, thoughts become words, words become action, action becomes habit and habit becomes destiny'. In other words, if one can control our thoughts by using certain ways and means, then it is possible to live a healthy life by all means. If our thoughts are positive and empowering, then the chakras will get a proper stimulus and will get activated. This state of the chakras is commonly called 'open' or 'balanced'. It leads one to experience a good flow of energy. If our thoughts are negative that is full of fears, worries and doubtfulness, then we experience slowing down, depression, anxiety, unwillingness in work. In such situations, concerned chakras are said to be 'blocked' or 'imbalanced'.

There are three important factors of human life, viz movements, functions and physiological aspects. Movement is controlled by central nervous system, whereas physiological aspects are controlled by brain and heart. Various bodily functions are controlled by endocrine glands and other organs. All these three aspects are connected to the chakras.

- Muladhar Chakra is responsible for feelings of security and basic survival. If this chakra is open, then it means that the energy flow is ideal and hence, we do not come across issues related to security and survival.

- Swadhishthana Chakra is responsible for pleasure, joy, desire, creativity, sexuality and emotional balance.

- Manipura Chakra is responsible for self-esteem, confidence and courage.

- Vishuddha Chakra is responsible for honesty, faith, artistic expression and communication.

- Anahata Chakra is responsible for emotional freedom, compassion, empathy, social relationships and love.

- Ajna Chakra is responsible for perception, imagination, wisdom, decision making, and intuition. 
- Sahasrara Chakra is responsible for bliss, enlightenment, spirituality, and universal energy.

There are some revealing signs and symptoms of one or more blocked chakras such as difficulty in sleeping and concentrating, chronic depression or anxiety, mood swings, trouble in communicating, difficulty in connecting with others, feeling "stuck" etc.

When any of the seven chakras are blocked or under-active, it can cause significant disturbances in the body, which can impair individual life.

The following section enumerates some general observations related to blocked chakras and health issues that one may encounter in consequence.

Muladhara Chakra: Feeling stuck and sluggish, stress due to over-reliance on external circumstances, persistent financial problems, feeling that one has been abandoned by parents, hatred and anger towards the body. Problems in the legs, feet, rectum, tailbone, and immune system and prostate gland and sciatica. It can lead to urinary diseases and kidney disorders, constipation, fatigued, problems in the colon, lower back pain, hip pain and arthritis.

Swadhishthan Chakra: Difficulty allowing oneself to become emotionally and sexually intimate, the belief that sex is bad, that it can hurt, or the feeling that one has to be sexy to be loved, feelings of abuse, hurt and confusion. Distrust that you can't be loved for being yourself, a struggle toward a healthy self-image and a string of unsuccessful, toxic relationships. There is a general feeling of blocked creativity and constant fear of betrayal. It can lead to infertility, disease related to tissues, genital disorders and problems with reproductive organs. This Chakra is especially important for women because problems related to fibroids, difficult or painful menstruation can be related to blockages in this chakra.

Manipura Chakra: Feeling powerless or victimized, giving one's power away to others as one feels this is necessary to keep peace in relationships. Difficulty taking action on one's dreams due to low self-esteem, constant fear of rejection, stomach pains and anxiety, issues with willpower or self-esteem, and blood sugar. It can give rise to digestive system disorders like gases, bloating, ulcers, eating disorder, diabetes and low immunity. There can be problems related to pancreas and gallbladder.

Anahata Chakra: Fear of commitment and feeling that you must please others to be loved, hurt from past relationships and a feeling that one has to guard oneself against being hurt. Constant fear of being alone, trouble with giving and receiving love and being compassionate, the need to hold grudges. It can lead to heart, asthma, high blood pressure, allergies, arm and wrist pain, hypertension and lung diseases.

Vishuddha Chakra: Fear of speaking up and saying what one wants or feels, feeling inclined to go along with others so that one doesn't upset others, frustration because one doesn't feel that other people hear what you have to say. Sore throat or feeling like one's throat is blocked and Issues expressing oneself. This may give rise to lung disorders, neck and shoulder pain, goitre, thyroid problems and mouth or jaw issues. Issues expressing oneself and constant fear of being out of control.

Ajna Chakra: A struggle to find meaning in life and have a feeling of "why am I here?", disconnect from one's intuition, moodiness and stubbornness, difficulty making decisions, feeling lost when it comes to spiritual purpose and path in life. Frustration that there is something wrong or out of alignment. It may give rise headaches and eye strain, epilepsy, fainting, paralysis and sinus issues. 
Sahasrara Chakra: Feeling of loneliness, insignificance, and aimlessness, a strong attachment to material possessions and achievements (and the tendency to define oneself according to them). A disconnect from the spiritual side of life, lack of connection or guidance from a higher power, feeling unworthy of spiritual help and angry that the higher power has abandoned one. It becomes difficult to mediate as the mind is occupied by rigid thoughts and constant fear of alienation. This can lead to hormonal imbalances, metabolic syndromes, migraines, tension headaches and difficulty with sleep and waking cycles.

Some general signs of blocked chakras are difficulty concentrating, sleep problems, a feeling of helplessness, inability to express oneself, lack of motivation and inability to accomplish goals. If one notices these imbalances or blockages in the Chakras, it is necessary to clear them by taking the following steps:

- Hold oneself accountable and accept responsibility for the wrong steps one has taken in life to get to this point.

- Begin to jot down the potential causes of it to become aware of the blockage.

- Consult or study the ways and means to remove the chakra blockages (not discussed in detail in this article as it is a separate study) and restore them to harmony.

- When the chakras are open, one's body is healthy and life is balanced. Certain signs and observations indicate that the chakras are open or balanced.

Muladhar Chakra: One feels a strong connection with one's family, has trustworthy family friends, feels wanted and loved, feels content, confident with money one possesses, always has enough for what one needs and wants and feels safe on one's path. One has a relatively healthy body with good vitality and a basic sense of security and safety in the world. One feels grounded and the practical side of life functions smoothly. The individual has healthy bones, feet, legs, colon, adrenal glands, elimination and weight.

Swadhishthan Chakra: One has a strong sense of sexuality and recognizes it as one of the most powerful creative energies. One has balanced sexuality, neither under- nor over-active but creatively active. The person has good life energy, can play and experience joy, can feel healthy emotions and is open to change. He or she has healthy lower back, reproductive and urinary systems.

Manipura Chakra: One has a strong sense of one's own power and how to use it in healthy ways, admires others with power and influence. One trusts one's intuition (inner guidance) and does not need others' confirmation and validation. One has a sense of self-worth, the ability to make things happen in the physical world, a healthy relationship to personal power (neither shrinking from it nor being an authoritarian) and does the right use of will. There is absence of diabetes, major allergies, hypertension and the person has healthy digestion, adrenals, immune and muscle systems.

Anahat Chakra: One is comfortable, balanced and healthy in one's relationships. One can give and receive love easily and feels heartfelt gratitude for how wonderful one's life is. One appreciates others and feels compassion for self and others without feeling sorry for anyone. One loves oneself unconditionally and finds it easy to forgive others. One has compassion for others, a sense of emotional fulfilment, kindness to self and others. One can accept others even when they are different and feels connected to nature. The person has a healthy heart, lungs, thymus, arms and hands.

Vishuddha Chakra: One is comfortable speaking one's truth and experience others listening. The person feels that one is heard and honoured for one's truth, knowing that they alone are responsible for expressing themselves in an open and 
honest way. The person enjoys pleasure in many different ways in life and is creative in all endeavours. He or she feels articulate, honest, truthful yet firm. One has the ability to express one's own truth, the ability to express self and to listen as well as talk with honesty and creative expression. The person has healthy neck, shoulders, mouth, ears, nose, sinuses, thyroid and voice.

Ajna Chakra: One trusts and acts with confidence, has a strong sense of one's own inner truth and listens to and follows it as a guide to life path. One has inner wisdom and clarity on one's path and feels focused and determined. One is also open to receiving advice from others. The person feels a strong connection with celestial love and has intellect balanced with other attributes of intelligence such as insight, intuition, good concentration and memory. The person has healthy eyes, pituitary gland and hypothalamus.

Sahasrara Chakra: One feels connected to a higher power and has a sense that one is being watched over and cared for. One knows he or she deserves immense blessings and feels immense gratitude for the universal love and appreciation one feels towards self and others. One is connected to the source and achieves enlightenment. One has an unshakeable trust in one's inner guidance. The person has a sense of meaning in life, a sense of connection to a higher power or larger purpose, and to the rest of beings. He or she generally has a highly developed consciousness, inner peace and acceptance for others and is wise, mentally stable. The person has healthy cerebral cortex and pineal gland.

It would be quite appropriate to say that the changes of consciousness and awareness in each of the chakras is vital to understand how our bodies, emotions, mind and spirit inter-relate. One can take the analogy of a fluorescent tube. Imagine that a vertical power line (current) that runs up and down the spine, from the top of the head to the base of the spine. Think of this as your main source of energy. The seven major chakras are in the centre of the body and are aligned with this vertical power line. Anodea Judith in her book, 'Chakra Yoga' describes the chakras as "the centres for reception, assimilation and transmission of life energy".

Rosalyn.L.Bruyere, a healer in her book, rightly says that "As we explore the Chakras one by one, we see a healthy system implies much more than freedom from disease; vitality; 'appropriate feelings'; appropriate thought processes; a willingness to embrace change in our lives; creative self-expression; creative self-responsibility; intuitive understanding; healthy spiritual relationships; to be full of light, life and wellbeing".

The New Age movement has led to an increased interest in the West regarding chakras. Many people in this movement point to a correspondence between the position and the role of the chakras and those of the glands in the endocrine system.

\section{CONCLUSIONS}

The chakras are like seven interconnected energy centres that run our lives. It is through the Chakras that the network of energy interconnects our mind, body and emotions. The lower three chakras act upon our survival and the physical, emotional and intellectual aspects of life, whereas the higher chakras act upon our intelligence and power of intuition. Each chakra is unique and is responsible for several physical and emotional functions.

It is an observation of the authors that generally when people suffer from problems related to health, relations and emotions, they approach doctors, psychiatrists, physiotherapists and counsellors, often without any results despite being treated with medicines and other kinds of treatments. In such cases, we can relate the problems and symptoms (as discussed in detail earlier in this paper) to the respective chakra. This, in turn, can suggest certain ways and means to 
restore the balance. Proper diet, Asanas (Yogic body postures), Pranayama (breathing exercises mentioned in Yoga), positive thinking, certain affirmations to boost up positivity and confidence can help in balancing the affected chakra to provide relief. Operating the other way round, one can consciously observe the physical and emotional states relating to the chakras so as to find the answer and the remedy before landing up in problems related to health, emotions and disease.

When one of the chakras is blocked, other chakras begin to compensate for it and they either become overactive or underactive. Hence, the best way to start balancing all one's chakras and work towards well-being is to start at the root and work one's way up to the crown, one chakra at a time. The authors have observed that concentrating on the lower three chakras and trying to keep them balanced and properly activated will open the channel to the other four chakras.

\section{ACKNOWLEDGEMENT}

Authors acknowledge the help provided by Dr Manoj Patharkar.

\section{REFERENCES}

1. C. W. Leadbeater - The Chakras, Anand Gholap Theosophical Institute

2. Arthur Avalon (Sir Arthur Avalon) -The Serpent Power (1974) by Dover Publications

3. SAT-CHAKRA-NIRUPANA (By Purnananda Swami)

4. Chakras, Balance Your Body's Energy for Health and Harmony: Mercier, Patricia, Sterling Publishing Co Inc, New York, USA

5. The Yog Sutras of Patanjali, Swami Satchidananda, Integral Yoga Publication, Virginia, USA

6. Maxwell $R$ (2009) The physiological foundation of yoga chakra expression, Zygon 44 (4):807 - 824

7. Chakra Genesis, A Correlation Between Evolution of Chakras \& Embryogenesis by Acharya Balkrishna et al. Journal of Yoga and Physiotherapy Vol 6 Issue 4 Nov 2018

8. Chakras: Energy Centers of Transformation By Harish Johari, Simon and Schuster.

9. Buck, H. M. (1981). Spiritual discipline in Hinduism, Buddhism and the West. Chambersburg, PA: Anima Publications.

10. The essentials of Hinduism: A comprehensive overview of the world's oldest religion. Swami Bhaskarananda, Viveka Press. Seattle, WA

11. Chakra Yoga by Anodea Judith,Llewellyn Worldwide.

12. Wheels of Life: A User's Guide to the Chakra System by Anodea Judith

13. The Wisdom of the Chakras by Ellen Tadd, Lantern Books

14. Linnell, M. Relating to the Chakras. (1990) Self and Society Vol 21, No 6, January 1990.

15. Infinite Kingdom: Ignite the Night, by Danielle Fagan, Balboa Press.

16. Use of Chakras in psychotherapy - An Introduction by Shirley A Ward; issue 48 Spring 2006 Irish association of Humanistic and Integrative Psychotherapy

17. Wheels of Light, A Study of the Chakras, Rosalyn L. Bruyere

18. Hands of Light: A Guide to Healing Through the Human Energy Field by Barbara Ann Brennan, Bantam Books, 1988 
19. Light Emerging: The Journey of Personal Healing by Barbara Ann Brennan Random House Publishing Group,2011

20. The Book of Chakras by Ambika Wauters, Barron's, 2002 - Body, Mind \& Spirit

21. Chakras: Using the Chakras for Emotional, Physical, and spiritual well-being by Tori Hartman - 2019 Macmillan, Published by St. Martin's Publishing Group.

22. The Chakra Book: Energy and Healing Power of the Subtle Body By Osho, Osho Media International.

23. Chakras: The Pathways to Success By Anodea Judith, Lion Goodman, Jaico Publishing House.

24. https://www.freepik.com/free-photos-vectors/sahasrara 

